\title{
EL PAPEL DE LAS FUERZAS ARMADAS EN LA ACCIÓN HUMANITARIA
}

ITHE ROLE OF THE ARMED FORCES IN HUMANITARIAN ACTION

\author{
Esther Puertas Cristóbal \\ José Joaquín Fernández Alles \\ Universidad de Cádiz. España/Spain \\ esther.puertas|@uca.es \\ joaquin.alles@uca.es
}

\author{
Recibido/Received: 10/06/2010
}

Aceptado/Accepted: 23/07/2010

\section{RESUMEN}

Como contenido del Estado social en su dimensión internacional, y en cumplimiento de las resoluciones de Naciones Unidas y de la Unión Europea, España participa activamente en la aplicación de los acuerdos de paz, en la gestión de las tareas de reconstrucción post-conflicto, en las operaciones de ayuda humanitaria y en la lucha contra la piratería. Precisamente, uno de los contenidos más relevantes de la IX Legislatura de las Cortes Generales en España ha correspondido al ejercicio de la función parlamentaria de control, autorización e información del Congreso de los Diputados sobre las operaciones de paz y reconstrucción ejecutadas en el exterior por las Fuerzas Armadas. En síntesis, se trata de un decisivo avance en el proceso de parlamentarización y socialización de la política de seguridad y de la consideración de las Fuerzas Armadas como instrumento del Gobierno al servicio de los derechos humanos, la cooperación al desarrollo y la paz.

\section{PALABRAS CLAVE}

Acción Humanitaria, España, Naciones Unidas, paz, seguridad, Parlamento.

\section{SUMARIO}

1. El papel de las Fuerzas Armadas en la acción humanitaria. 2. Los fundamentos sociológicos de las operaciones de paz y reconstrucción. 3. Los fundamentos jurídicos de las operaciones de paz y reconstrucción. 4. Las operaciones de paz y reconstrucción en el exterior: la Ley Orgánica 5/2005. 5. Reflexiones conclusivas. Bibliografía.

\begin{abstract}
As content of the Social State in its international dimension, and in compliance with UN Resolutions and the European Union, Spain participates actively in the implementation of peace agreements in the management of the tasks of reconstruction post-conflict, humanitarian aid operations and the fight against piracy. Justly, one of the most relevant contents of the IX Legislature in Spain has been the exercise of parliamentary control by the Congress of Deputies on Peace and Reconstruction Operations performed abroad by the Armed Forces. In summary, this is a decisive advance in the process of parliamentarisation and socialization of security policy and the consideration of the Armed Forces as an instrument of government in service to human rights, development cooperation and peace.
\end{abstract}

\section{KEYWORDS}

Humanitarian action, Spain, United Nations, human rights, peace, safety, Parliament. 


\section{CONTENTS}

1. The role of the armed forces in humanitarian action. 2. Sociological basis of peace operations and reconstruction. 3. Legal basis of peace operations and reconstruction. 4. The peace and reconstruction operations abroad: organic law 5/2005. 5. Conclusions. References.

\section{EL PAPEL DE LAS FUERZAS ARMADAS EN LA ACIÓN HUMANITARIA}

En todas las épocas y culturas se pueden encontrar acciones que hoy se calificarían como humanitarias ligadas a la idea de solidaridad y filantropía. A lo largo de la historia el concepto de "humanitarismo" ha ido transformándose desde la mera esfera del asistencialismo, es decir la caridad o la beneficencia, hasta la actualidad, cuando las acciones humanitarias pueden ir ligadas a la denuncia social y al cambio en los procesos de desarrollo humano (Puertas Cristóbal, Atorga Daza, 2010: 23-27). Pero hay una fecha clave que supone el nacimiento de los principios actuales de la Acción Humanitaria -asistencia, protección y testimonio, humanidad e imparcialidad, universalidad, neutralidad e independencia: la publicación en 1862 de la obra Un recuerdo de Solferino de Henry Dunant (un empresario suizo que, al presenciar el desbordamiento de los profesionales sanitarios, organizó un pequeño dispositivo de emergencia con las mujeres de Castiglione, para socorrer a los militares heridos de ambos bandos en la Batalla de Solferino (1859), librada entre el ejército austriaco y el franco-sardo en el norte de Italia). De estas reflexiones surgen varias iniciativas: 1. La creación del Comité Internacional de la Cruz Roja (CICR) como primer actor humanitario propiamente dicho (1880). 2. La aprobación del primer Convenio de Ginebra para la protección de los militares heridos (1864), base jurídica del Derecho Internacional Humanitario (DIH). 3. La incorporación de numerosas disposiciones sobre los servicios de Sanidad Militar.

Pero ha sido durante la década de los años noventa del Siglo XX cuando la Acción Humanitaria ha experimentado un mayor desarrollo. El final de la Guerra Fría y la bipolaridad de las dos superpotencias ha dado lugar a un nuevo escenario internacional, que ligado al incremento de conflictos civiles, al aumento, frecuencia y virulencia de los desastres naturales en los últimos años, y a la aparición de las llamadas emergencias complejas, ha traído consigo, por un lado, el aumento de los donantes y de la Ayuda Oficial al Desarrollo (AOD), especialmente en la partida de ayuda humanitaria- en detrimento de la cooperación al desarrollo-, que se situaba en torno al $2 \%$ en la década de los años noventa y que actualmente ha superado el 10\% (El informe anual de 2008 del Comité de Ayuda al Desarrollo -CAD- de la Organización para la Cooperación y Desarrollo Económico -OCDE-, que agrupa a veintidós países donantes, subraya que la AOD respecto a 2007 se incrementó en un 10,2\% alcanzando un total histórico de 119.8 billones de dólares, valorando positivamente el incremento de un 19,4\% de la AOD española en cuanto a volumen de donación que ocupa el séptimo lugar dentro del grupo de países integrantes del CAD). Por otro lado, ha conllevado la multiplicación y diversificación de los actores que intervienen en la Acción Humanitaria (Gobiernos, Organizaciones Internacionales, ONGs, Universidades, Medios de Comunicación, Fuerzas Armadas... que plantean distintos espacios compartidos de respeto y de conocimiento mutuo, de claridad en sus mandatos, y de una ardua tarea de coordinación), sin que, aparentemente, se haya traducido en una mayor eficacia y eficiencia en la ayuda que revierta definitivamente sobre la mejor calidad de vida de los beneficiarios (atendiendo a los principios de la Declaración de París de 2005 sobre la eficacia de la ayuda y al Programa de Acción de 
Accra 2008), la movilización de la opinión pública internacional y el nacimiento de las operaciones de paz promovidas por el Consejo de Seguridad de las Naciones Unidas.

En los últimos tiempos, las Fuerzas Armadas de diversos países han participado en misiones en el exterior con funciones de mantenimiento, construcción o consolidación de la paz (Capítulo VI de la Carta de Naciones Unidas) y, en menor medida, de imposiciones de paz (Capítulo VII de la Carta). Hasta 1990, estas misiones militares podían coincidir en el terreno con el trabajo de las organizaciones humanitarias, pero no se vinculaban directamente ni debían incluir en su mandato consideraciones humanitarias; posteriormente, introdujeron el llamado "enfoque integrado", que incluye cuestiones de carácter humanitario: en algunos casos de forma indirecta (protección, seguridad, acceso...) y en otras de forma más directa como la colaboración en la asistencia. El elemento fundamental de estos cambios en las operaciones de paz fue el hecho de que los civiles pasaran a ser el blanco en muchos de los conflictos y se convirtieran en las víctimas mayoritarias de los mismos (Rey Marcos, Thieux, Nuñez Villaverde, 2007: 9 y ss.)

Por otra parte, las Fuerzas Armadas se han convertido en actores controvertidos de la Acción Humanitaria y están siendo cuestionadas por otros agentes humanitarios que ya se dotan de protección armada y sienten que su presencia directa puede poner en peligro la imparcialidad de estos últimos. La confusión entre la acción propiamente militar y la civil ha planteado problemas en contextos de conflictos armados y en situaciones de emergencias complejas (que han proliferado desde la caída del muro de Berlín en 1989) en las que los ejércitos juegan un papel fundamental. Su calificativo de "complejas" se debe a tres razones. En primer lugar, la multiplicidad de sus causas, que se encuentran en la interrelación de diversos factores políticos, económicos y socioculturales como el desmoronamiento de la economía formal y de las estructuras estatales, los conflictos civiles, las hambrunas, las crisis sanitarias y el éxodo de la población (...). En segundo lugar, el carácter omnicomprensivo de su impacto, que, a diferencia de los desastres desencadenados por catástrofes naturales, afecta gravemente a todos los órdenes de la vida, con un fuerte efecto destructivo y desestructurador. $\mathrm{Y}$, en tercer lugar, la consiguiente necesidad de que la respuesta internacional se base en un mandato múltiple, que permita actuar en varios frentes, como son la Acción Humanitaria, la diplomacia de alto nivel, o incluso el uso de la fuerza armada para el mantenimiento de la paz (Pérez de Armiño, Areizaga, 2002: 217-220).

Guerras como las de Bosnia-Herzegovina, Ruanda, Somalia, Afganistán o Liberia pusieron en entredicho la soberanía de estos Estados y demostraron su fragilidad en situaciones de crisis, al tiempo que constataron la voluntad de los gobiernos occidentales por ejercer su derecho de injerencia basándose en motivos humanitarios. Además, si se evalúa la asignación de fondos que se han determinado en cada ocasión para gestionar la crisis y la rehabilitación post-desastre, se aprecian las diferencias en función de los intereses económicos y geopolíticos de los donantes en las zonas afectadas. En estos casos la Acción Humanitaria ha sido desigual, discriminatoria y ha corrido el riesgo de politizarse. Por tanto, las actuaciones humanitarias no sólo tienen que basarse en la legitimidad que le otorga el Derecho Internacional, sino que deben acompañarse de la legitimidad derivada de la ética y la moral; y principios como los de imparcialidad, neutralidad, independencia, humanidad, universalidad o dignidad tienen que estar presentes en cualquier acción (Puertas Cristóbal, Astorga Daza, 2010: 23-27). Por otra parte, la posterior acción militar en Kosovo de la mano de la OTAN, sin autorización de Naciones Unidas o las acciones unilaterales en Irak y Afganistán, han complicado aún más esta cuestión. El abuso del calificativo humanitario, dirigido a buscar una mayor legitimidad a operaciones básicamente militares, ha desdibujado y vuelto más borrosa 
la división que existe y debe mantenerse entre los ámbitos político, militar y humanitario. Las operaciones militares pueden detener la matanza, controlar la violencia y proteger espacios de seguridad; la Acción Humanitaria, sin embargo, incluso con recursos limitados, puede llegar a lugares inaccesibles y durante el conflicto asistir a las víctimas bajo los principios de neutralidad e imparcialidad, sin importar su procedencia ni pertenencia a uno u otro bando (Rey Marcos, Thieux, Nuñez Villaverde, 2007: 9 y ss.)

Tanto con la aprobación en la Asamblea General de Naciones Unidas de la Resolución 46/182, que supuso la confirmación de su liderazgo al frente de las situaciones de emergencia y crisis humanitarias internacionales, como con la aprobación de las Directrices de Oslo de 1994 y de 2003, se refuerza la idea de sumar esfuerzos en la respuesta ante desastres, establecer criterios claros para el uso de medios militares y de defensa civil en apoyo del trabajo humanitario de las Naciones Unidas en los conflictos armados y determinar los sistemas de coordinación entre los medios civiles y militares. Esta normativa específica de referencia y todo el conjunto de documentos de Naciones Unidas y del Comité Permanente Interagencias (IASC) constituyen, según los Estados firmantes de los Principios de la Buena Donación Humanitaria (2003) un marco doctrinal que contribuye a clarificar las competencias de las Fuerzas Armadas en la Acción Humanitaria.

\section{LOS FUNDAMENTOS SOCIOLÓGICOS DE LAS MISIONES DE PAZ Y RECONSTRUCCIÓN}

Las Fuerzas Armadas españolas gestionan misiones de paz y seguridad internacional en el exterior desde 1991 (hasta los años ochenta España se ha considerado un país receptor de ayuda al desarrollo. Su adhesión a la OTAN en 1982, a los distintos Bancos Regionales de Desarrollo, a la Unión Europea en 1986) y al Comité de Ayuda al Desarrollo de la OCDE en 1991 contribuyen a su apertura e internacionalización y configuran una imagen distinta a la de entonces). La dimensión social de estas misiones, asumida por el Estado en las operaciones en el exterior, viene determinada por los mandatos de Derecho Constitucional e Internacional, cuyos objetivos de paz y seguridad se dirigen al cumplimiento y la garantía de libertad, justicia y progreso de los pueblos en situaciones de guerras, crisis humanitarias o piratería.

Se trata de uno de los contenidos más novedosos del Estado social proclamado por la Constitución de 1978 y una actividad estatal internacional que, además, cuenta con un amplio respaldo social según acreditan las encuestas realizadas por el Centro de Investigaciones Sociológicas. Así, en el Estudio número 2680 del CIS, sobre La Defensa Nacional y Fuerzas Armadas (VII), de 10 de marzo de 2007, se extrajo que el $84.7 \%$ de los encuestados está más bien de acuerdo con que España participe en misiones internacionales de paz frente al $10.4 \%$ que manifiesta estar en desacuerdo. Asimismo el 46.7\% opinaba que las Fuerzas Armadas españolas habían mejorado, el $43.3 \%$ concluía que se habían mantenido igual y sólo el $4.6 \%$ consideraba que habían empeorado.

En una encuesta reciente, de diciembre de 2009, identificada como Estudio número 2825 sobre La defensa nacional y las Fuerzas Armadas (VIII), arroja prácticamente los mismos resultados: el $84.6 \%$ de los encuestados está más bien de acuerdo con que España participe en misiones internacionales de paz frente al $10.4 \%$ que refleja desacuerdo, mientras que el $45.3 \%$ piensa que las Fuerzas Armadas españolas han mejorado, el $44.8 \%$ opina que se mantiene igual y únicamente el $4 \%$ considera que han empeorado. 
En este sentido, las últimas encuestas publicadas por el Real Instituto Elcano $\left(22^{\circ}, 23^{\mathrm{a}} \mathrm{y}\right.$ $24^{\circ}$ Oleada del Barómetro en noviembre de 2009, marzo y junio de 2010 respectivamente) confirman la excelente valoración de las misiones de las FFAA en el exterior: entre el 51 y el 55\% de los encuestados en cada uno de los barómetros ha evaluado positivamente la actividad de la FAS en el Océano Índico, frente al 30-32\% también respectivamente que rechaza esta misión por su complejidad y peligro. El caso de Afganistán y Líbano guarda unos resultados similares (con apoyos del 38\% y 37\%) y Haití algo mayores (45\%). En cualquier caso, tras veinte años de intervención de las FFAA españolas en misiones en el exterior, estas cuentan con la aprobación mayoritaria del 74\% de la población.

En definitiva, estos datos confirman en uno y otro caso, que en el último periodo de dos años, la población española conoce y valora positivamente el papel de las Fuerzas Armadas en el exterior. Esto puede ser debido a la función de los medios de comunicación como actor no tradicional de la Acción Humanitaria. Los medios de comunicación son hoy día un elemento básico en la conformación de los poderes establecidos en las sociedades desarrolladas. Han adquirido lo que se podría denominar un rol propio, definitorio, prácticamente natural. Ese rol adquirido por los medios convierte a la comunicación en parte y en núcleo de la información. Se produce una realidad dirigida a una sociedad cada vez más propensa a la emotividad; a ello contribuye la fuerza de las noticias contadas en imágenes. Hay un exceso de información, lo que implica un interés creciente por saber por parte de la ciudadanía, en lo que se ha denominado como Sociedades de la Información (o Sociedades del Conocimiento). De hecho, los sectores relacionados con las tecnologías de la información y la comunicación tienen en esta sociedad global un papel primordial como educadores sociales y agitadores de la opinión pública (Puertas Cristóbal, Astorga Daza, 2010: 123-130).

En otro orden de cosas, esta aceptación social de las misiones de paz tiene su correlato normativo en las leyes que los representantes políticos aprobaron en la VIII Legislatura (2004-2008), principalmente la LO 5/2005, de 17 de noviembre, de la Defensa Nacional, cuyo artículo 15 dispone que las Fuerzas Armadas contribuyen militarmente a la seguridad y defensa de España y de sus aliados, en el marco de las organizaciones internacionales de las que España forma parte, así como al mantenimiento de la paz, la estabilidad y la ayuda humanitaria. Conforme al artículo 16, sobre los tipos de operaciones, el cumplimiento de las misiones de las Fuerzas Armadas y el desarrollo de su contribución complementaria o subsidiaria de interés público requieren la realización de diferentes tipos de operaciones, tanto en territorio nacional como en el exterior, que pueden conducir a acciones de prevención de conflictos o disuasión, de mantenimiento de la paz, actuaciones en situaciones de crisis y, en su caso, de respuesta a la agresión. En particular, las operaciones pueden consistir en la colaboración en operaciones de mantenimiento de la paz y estabilización internacional en aquellas zonas donde se vean afectadas, la reconstrucción de la seguridad y la administración, así como la rehabilitación de un país, región o zona determinada, conforme a los tratados y compromisos establecidos (artículo 16 b). También la Ley 23/1998, de 7 de julio, de Cooperación Internacional para el Desarrollo, apuesta por una defensa de la paz y se asume como objetivo la contribución a "un marco de estabilidad y seguridad que garantice la paz internacional" (artículo 3 b). Como reconoce la Exposición de Motivos del Real Decreto-ley 8/2004, de 5 de noviembre, la presencia internacional de nuestro país ha crecido en las últimas décadas y se ha traducido en un notable incremento de la presencia de españoles que prestan sus servicios fuera del territorio nacional, en especial en operaciones de paz y seguridad internacionales, 
asistencia humanitaria o en otras misiones oficiales de representación o de servicio exterior del Estado que se ven expuestos a situaciones de peligro.

Pues bien, este conjunto de operaciones de paz encuadradas generalmente en el concepto de acción humanitaria representa una actividad del Estado gestionada por el Gobierno de la Nación, quien necesita legitimarse jurídicamente en el Derecho Internacional, regularse por ley estatal y someterse a las garantías jurisdiccionales y de control parlamentario que son propias del Estado de Derecho (Puertas Cristóbal, Astorga, 2010: 21 y ss.). No obstante, el estudio del tratamiento sociopolítico sobre estas operaciones militares de paz en el exterior y su control por la sede parlamentaria, cuya regulación afecta a derechos y principios jurídicos universales, adolece en nuestro ordenamiento de una defectuosa conceptuación y de una falta de delimitación terminológica que resta seguridad jurídica y precisión material a efectos normativos e investigadores. Bastarán algunos ejemplos varios demostrativos para comprobar esta insuficiencia normativa: la definición de Naciones Unidas sobre las operaciones de mantenimiento de la paz no cuenta aún con una adhesión clara por parte del legislador, que doctrinalmente existe un debate abierto sobre el confuso carácter humanitario o militar de algunas misiones y que en la documentación parlamentaria sobre control de estas operaciones se siguen invocando por el Gobierno y las Cortes Generales expresiones ya superadas como "operación no ejecutiva". Otra muestra significativa de la falta de conceptuación jurídica sobre las misiones humanitarias en el exterior la encontramos en la legislación estatal aplicable, que no emplea con rigor las expresiones "acción humanitaria" y "ayuda humanitaria".

En la sede parlamentaria española, siguiendo la obsoleta terminología de la Ley 23/1998, de 7 de julio, de Cooperación Internacional para el Desarrollo, todavía se emplea sólo la expresión ayuda humanitaria. Véanse como ejemplos de esta falta de diferenciación conceptual en sede parlamentaria las preguntas que se han dirigido en los últimos años al Gobierno con petición de respuesta escrita sobre protección y apoyo a los barcos que quieran acceder a Gaza para la entrega de ayuda humanitaria, acerca de la publicidad sobre la ayuda humanitaria en Haití de la Agencia Española de Cooperación Internacional para el Desarrollo, en relación con la acción de hostilidad militar del Gobierno israelí frente a la ayuda humanitaria internacional a la población civil en la Franja de Gaza, sobre la ayuda humanitaria destinada a la Franja de Gaza o, finalmente, en el caso de la Proposición no de Ley sobre medidas encaminadas a facilitar la canalización de la ayuda humanitaria en Cuba, que permitan a sus habitantes hacer frente en mejores condiciones a los graves destrozos ocasionados por los huracanes Ike y Gustav.

En efecto, la diferencia entre "acción humanitaria" y "ayuda humanitaria", aunque incluida en los Planes Directores (2005-2008) y (2009-2012), todavía no ha sido incorporada a la Ley 23/1998, de 7 de julio, de Cooperación Internacional para el Desarrollo. Según el artículo 12 de la Ley 23/1998, la ayuda humanitaria consiste en el envío urgente, con carácter no discriminado, del material de socorro necesario, incluida la ayuda alimentaria de emergencia, para proteger vidas humanas y aliviar la situación de las poblaciones víctimas de catástrofe natural o causadas por el hombre o que padecen una situación de conflicto bélico. Esta ayuda la llevan a cabo las Administraciones públicas directamente o a través de organizaciones no gubernamentales y Organismos internacionales. La ayuda humanitaria podrá dar paso a actividades de rehabilitación, de reconstrucción de infraestructuras, restablecimiento institucional o de reinserción de poblaciones afectadas, debiendo promoverse la mayor coordinación posible entre las entidades que colaboren y respecto de las instituciones u organizaciones locales, a fin de tener en cuenta los objetivos del desarrollo 
a medio y largo plazo. Incluye asimismo este instrumento, la aportación de productos alimenticios y de implementos e insumos agrícolas a países en desarrollo con problemas de insuficiencia alimentaria, con el fin de potenciar su autoabastecimiento y garantizar su seguridad alimentaria, como base de su proceso de desarrollo.

En este sentido, conviene recordarse qué se entiende por "acción humanitaria": el conjunto de actividades de protección y asistencia, a favor de las víctimas civiles y militares de desastres, conflictos armados y de sus consecuencias directas, orientadas a aliviar el sufrimiento, garantizar la subsistencia y proteger los derechos humanos. Se puede afirmar que los servicios humanitarios están caracterizados por la diversidad de acciones y la unidad en la intención que persiguen tales acciones (Puertas Cristóbal, Astorga, 2010: 21-72). En cualquier caso, debe recordarse que la "acción humanitaria" como tal es más que la "ayuda humanitaria" (entendiendo por esta la usual distribución de bienes y de servicios en situaciones de crisis en cantidad y calidad adecuada) y, en todo caso, implica ayuda de emergencia, asistencia a refugiados y desplazados, garantía del acceso de la población civil a tales bienes -distribución y protección de los beneficiarios, testimonio (desde el advocacy hasta la denuncia, tratando de sensibilizar a la ciudadanía), prevención y preparación ante desastres, rehabilitación inmediata postdesastre. Además, supone la asunción de una serie valores y principios (humanidad, universalidad, imparcialidad, neutralidad,..) y no sólo el cumplimiento del fin referido al tipo de proyecto y a los beneficiarios, sino también el medio: el cómo se realiza (Martínez Isidoro, 2009: 1-12).

A la espera de la necesaria reforma normativa que incluya un precepto con definiciones sobre las categorías aplicables, debemos recordar, como contenido del acervo conceptual que debe asumir el legislador, que en el Derecho internacional se ha asentado en los últimos años la noción de Operaciones de Paz, asumida por la Declaración sobre los Objetivos del Milenio (Declaración del Milenio. Naciones Unidas. A/RES/55/2. Asamblea General Distr. General 13 de septiembre de 2000. Quincuagésimo quinto período de sesiones. Resolución aprobada por la Asamblea General. Declaración del Milenio. Apart. 6), que anteriormente se definían como operaciones de mantenimiento de la paz, y que son entendidas como acciones destinadas al despliegue sobre el terreno, con el consentimiento o la aquiescencia de todas las fuerzas implicadas, de una presencia internacional (normalmente de las Naciones Unidas o con autorización de Naciones Unidas), incluyendo en la mayoría de los casos personal militar, policial y civil, al objeto de prevenir, contener o estabilizar una situación de conflicto y apoyar los esfuerzos para encontrar una solución permanente a ese conflicto o a alguna de sus manifestaciones (Boutros-Ghali, 1992: 12-15).

Asimismo, debemos atender al concepto de Construcción de la Paz (CP, peacebuilding), que incluye tanto la prevención de conflictos violentos como la gestión de las crisis, resolución de conflictos y la consolidación de la paz, siendo este último concepto el correspondiente a la etapa posterior a la firma de un acuerdo de paz o al fin de la violencia generalizada, con un esfuerzo global para evitar la reanudación de las hostilidades. En este contexto, la Estrategia de Construcción de la Paz de la Cooperación Española dirige sus objetivos a coordinarse eficazmente con todos aquellos que atesoran capacidades y experiencias sectoriales al servicio de la paz y la resolución pacífica de los conflictos. El día 7 de marzo de 2000, el entonces Secretario General de la ONU, Kofi Annan, convocó a un grupo de alto nivel para que efectuara una profunda revisión de las actividades que realizan las Naciones Unidas, relacionadas con la seguridad y la paz. El grupo consultor fue presidido por el Sr. Lakhdar Brahimi, ex Ministro de Argelia e integrado por diez personalidades con experiencia en el mantenimiento y consolidación de la paz, así como en el desarrollo y la asistencia humanitaria. 
Según este Informe Brahimi (www.un.org/spanish/peace/operations report/docs/full_report. htm), en sus Conclusiones del "Grupo de trabajo sobre operaciones de Paz" de la ONU (agosto de 2000), las Operaciones de Paz de ONU pueden ser de tres tipos: a) "Misiones de prevención de conflictos y establecimiento de la paz, que son iniciativas diplomáticas que intentan poner coto a los conflictos en curso, mediante instrumentos de la diplomacia y la mediación"; b) "Misiones de mantenimiento de la paz", para observar las cesaciones del fuego y la separación de las fuerzas después de la guerra entre estados; y c) "Misiones de consolidación de la paz", como actividades realizadas al final de un conflicto para restablecer las bases de la paz y ofrecer los instrumentos para construir sobre ellas algo más que la mera ausencia de la guerra. Y según afirmó el Ministro de Asuntos Exteriores y de Cooperación, "el concepto de misión de paz es un concepto vivo, en evolución. Las misiones de paz son cada vez más complejas y algunas de las últimas autorizadas por el Consejo de Seguridad han demostrado que no responden ya a la limitada noción con la que estas operaciones fueron concebidas hace ya 60 años. Términos como "operación híbrida", "multidimensional", "de mantenimiento, creación y consolidación de la paz", se aplican cada vez con mayor frecuencia, sin que la comunidad internacional haya podido dar respuesta adecuada a los retos que estas situaciones complejas plantean" (Intervención del Ministro de Asuntos Exteriores y de Cooperación de España D. Miguel Angel Moratinos con motivo del debate organizado por Reino Unido, en su calidad de presidencia del consejo de seguridad, sobre "Estabilización Post- Conflicto: Paz Tras La Guerra. http://www.spainun.org/pages/ viewfull.cfm?Elem entID=2380). Por su parte, en el particular contexto de la Unión Europea donde se inserta España, las "misiones de Petersberg" de la Política Europea de Seguridad y Defensa (PESD), que se crearon mediante la Declaración de Petersberg adoptada tras el Consejo de Ministros de la UEO de junio de 1992, responden a la siguiente tipología de misiones: misiones humanitarias o de rescate; misiones de mantenimiento de la paz; y misiones en las que intervengan fuerzas de combate para la gestión de crisis, incluidas las misiones de restablecimiento de la paz. Las operaciones de paz de las Naciones Unidas entrañan tres actividades principales: prevención de conflictos y establecimiento de la paz, mantenimiento de la paz, y consolidación de la paz. Naciones Unidas A/55/305-S/2000/809. Asamblea General. Consejo de Seguridad. Distr. General. 21 de agosto de 2000. Asamblea General. Quincuagésimo quinto período de sesiones. http://www.cinu.org.mx/temas/paz_segu ridad/a55305.pdf, pp. 2-4.

\section{LOS FUNDAMENTOS JURÍDICOS DE LAS OPERACIONES DE PAZ Y RECONSTRUCCIÓN}

Los fundamentos jurídicos y sociopolíticos de las operaciones de paz y reconstrucción de las políticas de seguridad y defensa, incorporados prontamente al Preámbulo de la Constitución de 1978, cuyo contenido proclama la colaboración en el fortalecimiento de unas relaciones pacíficas y de eficaz cooperación entre todos los pueblos de la Tierra, han sido concretados en unas políticas de relaciones exteriores, de defensa y de cooperación al desarrollo, en virtud de las cuales el Gobierno de España coopera orgánica y funcionalmente a través de un organigrama institucional de carácter internacional que excede de las fronteras nacionales en el marco de la denominada acción humanitaria. Desde el momento en que esta actividad del Estado se sujeta a un régimen de control político en el Parlamento, el funcionamiento del régimen de autorizaciones, ratificaciones e 
información sobre las operaciones militares ha permitido identificar la motivación que, desde 2005, justifica y fundamenta la participación, el envío y el despliegue de unidades, efectivos y contingentes en el exterior, a partir de las prescripciones establecidos en la propia LO 5/2005. En particular, esta fundamentación jurídica incorporada a las solicitudes del Consejo de Ministros se basa en principios y preceptos de Derecho Constitucional, del Derecho de la Unión Europea y del Derecho Internacional Público, en este caso, de las resoluciones de Naciones Unidas. Exige el artículo 19 de la citada Ley Orgánica: "Para que las Fuerzas Armadas puedan realizar misiones en el exterior que no estén directamente relacionadas con la defensa de España o del interés nacional, se deberán cumplir las siguientes condiciones: a) Que se realicen por petición expresa del Gobierno del Estado en cuyo territorio se desarrollen o estén autorizadas en Resoluciones del Consejo de Seguridad de las Naciones Unidas o acordadas, en su caso, por organizaciones internacionales de las que España forme parte, particularmente la Unión Europea o la Organización del Tratado del Atlántico Norte (OTAN), en el marco de sus respectivas competencias; b) Que cumplan con los fines defensivos, humanitarios, de estabilización o de mantenimiento y preservación de la paz, previstos y ordenados por las mencionadas organizaciones; y c) Que sean conformes con la Carta de las Naciones Unidas y que no contradigan o vulneren los principios del derecho internacional convencional que España ha incorporado a su ordenamiento, de conformidad con el artículo 96.1 de la Constitución.

En el ámbito de la Unión Europea, el artículo 21.2 c) del Tratado de la Unión Europea, dentro sus Disposiciones generales relativas a la acción exterior de la Unión y disposiciones específicas relativas a la Política Exterior y de Seguridad Común, dispone que la Unión definirá y ejecutará políticas comunes y acciones y se esforzará por lograr un alto grado de cooperación en todos los ámbitos de las relaciones internacionales con el fin de mantener la paz, prevenir los conflictos y fortalecer la seguridad internacional, conforme a los propósitos y principios de la Carta de las Naciones Unidas, así como a los principios del Acta Final de Helsinki y a los objetivos de la Carta de París, incluidos los relacionados con las fronteras exteriores. A su vez, en las Disposiciones sobre la política común de seguridad y defensa, el artículo 42 dispone que la Unión podrá recurrir a dichos medios en misiones fuera de la Unión que tengan por objetivo garantizar el mantenimiento de la paz, la prevención de conflictos y el fortalecimiento de la seguridad internacional, conforme a los principios de la Carta de las Naciones Unidas. Según el artículo 43.1, estas misiones en las que la Unión podrá recurrir a medios civiles y militares, abarcarán las actuaciones conjuntas en materia de desarme, las misiones humanitarias y de rescate, las misiones de asesoramiento y asistencia en cuestiones militares, las misiones de prevención de conflictos y de mantenimiento de la paz, las misiones en las que intervengan fuerzas de combate para la gestión de crisis, incluidas las misiones de restablecimiento de la paz y las operaciones de estabilización al término de los conflictos.

Sentada esta fundamentación, pasamos a describir la motivación empleada en cada uno de los casos habidos hasta el momento presente:

\section{a) Misiones en Somalia}

La fundamentación jurídica internacional y comunitaria es la siguiente: Internacional, a partir de la Resolución 1872, de 26 de mayo de 2009, del Consejo de Seguridad de Naciones Unidas, a través de su Consejo de Seguridad, por la que reconocía que la situación de inestabilidad en Somalia, que agravaba el problema de la piratería y el robo a mano armada frente a sus costas, destacaba la necesidad de una respuesta amplia de la 
comunidad internacional para combatir la piratería y sus causas subyacentes, e instaba a los Estados Miembros y a las organizaciones regionales e internacionales a que ofreciesen asistencia técnica para el adiestramiento y equipamiento de las fuerzas de seguridad somalíes; y Comunitaria, toda vez que en el seno del Consejo de la Unión Europea el 15 de febrero de 2010 se aprobó la Decisión 2010/96/CFSP, destinada a contribuir al adiestramiento de las Fuerzas de Seguridad de Somalia. En su cumplimiento, la Unión Europea ha ejcutado una misión de entrenamiento de carácter militar (European Union Training Mission, EUTM-Somalia), en coordinación con el Gobierno Federal de Transición somalí, la Unión Africana y, en particular, con su Misión para Somalia (AMISOM), las Naciones Unidas y los Estados Unidos.

\section{b) Misión ISAF-Afganistán}

La presencia de España en Afganistán está amparada por varias Resoluciones del Consejo de Seguridad de las Naciones Unidas, desde la Resolución 1386, de 20 de diciembre de 2001, por la que el Consejo de Seguridad autorizó el despliegue de una Fuerza Internacional de Asistencia a la Seguridad (ISAF), hasta la última la de Resolución 1890, de 8 de octubre de 2009, por la que se prorroga la misión hasta el 13 de octubre de 2010. Por su parte, en el Acuerdo que solicitó autorización para el despliegue de efectivos adicionales de las Fuerzas Armadas Españolas, dentro de la Misión ISAF-Afganistán, la presencia de las Fuerzas Armadas españolas en Afganistán, en el marco de la Fuerza Internacional de Asistencia para la Seguridad (ISAF), fue fundamentada en las Resoluciones del Consejo de Seguridad de las Naciones Unidas, citándose la Resolución 1833 (2008), de 22 de septiembre.

Junto a la justificación a priori se establece una justificación a posteriori sobre la base de la misión ya celebrada: "En enero de 2002 llegaron a territorio afgano los primeros efectivos españoles de ISAF. Desde entonces, y en función de la configuración de la misión, nuestro contingente ha ido evolucionando y adaptándose, en ubicación y en tipo de actividades (...)". Como reconoce el propio Acuerdo del Consejo de Ministros, el planteamiento y los propósitos fundamentales siguen siendo el apoyo a la seguridad, al desarrollo político e institucional y a las labores de reconstrucción y cooperación al desarrollo en Afganistán. Sigue siendo prioritario el compromiso de la Alianza para mantener el apoyo a un Afganistán respetuoso del Estado de Derecho e institucionalmente viable, que no se convierta en base terrorista ni refugio del extremismo violento, y se invoca el compromiso adoptado por España en la Cumbre de Estrasburgo-Kehl del 4 de abril de 2009. En síntesis, el Gobierno considera, por último, que un incremento del contingente español actualmente desplegado en Afganistán responde al compromiso adquirido por España, como miembro responsable de la Comunidad Internacional, con aquel país y el proceso de afganización, con sus aliados de la OTAN y con la Organización de las Naciones Unidas, garante último de la legalidad internacional. Está, además, en línea con los planteamientos de otros aliados.

Asimismo, en el Acuerdo que solicita la autorización del Congreso de los Diputados para el envío y participación de efectivos adicionales de las Fuerzas Armadas Españolas y de la Guardia Civil, dentro de la Misión ISAF-Afganistán, presentado en el Congreso el 12 de febrero de 2010, la fundamentación jurídica se concreta en las mismas Resoluciones del Consejo de Seguridad de las Naciones Unidas, siendo la última la 1833 de 22 de septiembre de 2008, en la que se prorrogaba la misión hasta el 13 de octubre de 2009, así como en el "Acuerdo entre el Reino de España y la República Islámica de Afganistán para 
el Patrocinio de una Unidad del Ejército Nacional Afgano", 24 de julio de 2008, por el que España patrocina - financia, equipa y entrena - una unidad del Ejército Nacional Afgano y financia la construcción de un acuartelamiento en Qala i Naw para uno de sus batallones. Junto a los fundamentos jurídicos sustentados en los acuerdos anteriores, en esta ocasión se indica que las naciones que contribuyen con tropas a la misión ISAF de la OTAN acordaron, con fecha 15 de junio de 2006, relevarse periódicamente en la responsabilidad de aportar efectivos para cubrir determinadas necesidades específicas.

\section{c) Misiones en Haití}

En este caso, el fundamento jurídico internacional es la iniciativa, del 17 de enero de 2010, del Secretario General de la ONU, quien propuso que la Unión Europea organizase una misión en Haití, bajo el amparo de la ONU, para llevar a cabo labores humanitarias y de reconstrucción urgente en Puerto Príncipe. Por su parte, el Comité Político y de Seguridad de la UE, en su reunión del 18 de enero, expuso la posibilidad de constituir un mecanismo ad hoc, sin estructuras de mando y control, que permita la coordinación y actuación con eficacia, manteniendo la autonomía de cada país en su contribución y la visibilidad de la Unión Europea en la zona. En virtud de estas fundamentaciones, el Acuerdo del Consejo de Ministros afirma que la participación de un contingente militar español es conforme con la Carta de Naciones Unidas, tiene una finalidad eminentemente humanitaria, se realiza como respuesta a la solicitud de ayuda y apoyo efectuada por el Gobierno de Haití, y se ajusta, por tanto a las condiciones que deben cumplir las misiones de las Fuerzas Armadas en el exterior, que figuran en la LO 5/2005.

\section{d) Operación Atalanta}

Está fundamentada en las Resoluciones 1814 (2008), 1816 (2008), 1838 (2008), 1846 (2008) y 1851 (2008). En particular, la Resolución 1814, dedicada a la difícil situación general en el área, exhorta a los Estados y organizaciones regionales a que tomen medidas, bajo el Capítulo VII de la Carta, a fin de proteger la navegación para el transporte y el suministro de asistencia humanitaria a ese país. En la Resolución 1816, el Consejo de Seguridad, teniendo en cuenta la falta de capacidad del Gobierno Federal de Transición de Somalia para interceptar a los piratas o patrullar y asegurar las rutas marítimas internacionales frente a las costas o aguas territoriales de este país, insta a los Estados miembros a actuar contra la piratería y el robo a mano armada, bajo el Capítulo VII de la Carta de las Naciones Unidas. En la Resolución 1838, se exhorta a los Estados a desplegar buques de guerra y aeronaves militares para, de acuerdo con la legalidad internacional, emplear todos los medios necesarios para reprimir los actos de piratería; en la Resolución 1846 amplía hasta diciembre de 2009 las autorizaciones relativas a la entrada en aguas territoriales de Somalia contempladas en la Resolución 1816; y en la Resolución 1851 establece medidas de coordinación y acciones que permiten intensificar las actividades que los Estados y organizaciones regionales llevan a cabo contra la piratería en colaboración con el Gobierno Federal de Transición de Somalia, para asegurar el tráfico marítimo internacional y los transportes efectuados por el Programa Mundial de Alimentos. Por otra parte, el Consejo de la Unión Europea aprobó la Acción Común 2008/851/CSFP de 10 de noviembre de 2008, decidiendo la realización de una operación militar denominada "Atalanta", para contribuir a la disuasión, prevención y lucha contra los actos de piratería y robo a mano armada que tienen lugar frente a las costas de Somalia. En la citada Acción Común, se expresa la decisión del Consejo de la Unión Europea de conducir, durante un 
período de 12 meses, una operación militar en apoyo de las Resoluciones 1814, 1816 y 1838 del Consejo de Seguridad de las Naciones Unidas, así como las necesarias medidas de control político, dirección estratégica, dirección militar, mando y control, de coordinación, administrativas y financieras. Asimismo, el Consejo de la Unión Europea aprobó su Decisión 918/2008, de 8 de diciembre de 2008, autorizando con esa fecha el lanzamiento de la Operación Atalanta.

\section{e) Misiones en Chad y la República Centroafricana}

La fundamentación se remite al Capítulo VII de la Carta de las Naciones Unidas y por un período de un año para adoptar todas las medidas que considere necesarias para realizar las siguientes tareas: Contribuir a la protección de los civiles que se encuentren en peligro, en particular los refugiados y desplazados; facilitar la prestación de ayuda humanitaria y la libre circulación del personal de asistencia humanitaria contribuyendo a mejorar la seguridad en la zona de operaciones; contribuir a la protección del personal, los locales, las instalaciones y el equipo de las Naciones Unidas, garantizando su seguridad y libertad de circulación, así como del personal asociado. Con la finalidad de responder al llamamiento efectuado por el Consejo de Seguridad de las Naciones Unidas, el 15 de octubre de 2007, el Consejo de la Unión Europea aprobó la Acción Común 2007/6671CSFP decidiendo la realización de una operación militar en el Chad y la República Centroafricana, denominada EUFOR Chad-RCA. En la citada Acción Común, se expresa la decisión del Consejo de conducir una operación militar de acuerdo con el mandato de la Resolución 1778 (2007) del Consejo de Seguridad de las Naciones Unidas, así como las necesarias medidas de control político, dirección estratégica, dirección militar, mando y control, de coordinación, administrativas y financieras. Por último, se cita la Decisión 101/2008, de 28 de enero, autorizando con esa fecha el lanzamiento de la operación EUFOR Chad- RCA.

\section{f) Misiones en el Líbano}

En la solicitud de autorización del Congreso de los Diputados para la participación de una unidad naval española en la fuerza marítima de UNIFIL (Líbano), integrada en EUROMARFOR, la participación de España en UNIFIL se fundamenta en las siguientes resoluciones: Resolución 1701 (2006) del Consejo de Seguridad de las Naciones Unidas, que ampliaba y mejoraba el Mandato asignado por las Resoluciones 425 (1978) y 426 (1978); que fue prorrogada por la Resolución 1773 (2007) en sus mismos términos hasta el 31 de agosto de 2008. La Fuerza Marítima de UNIFIL es una fuerza marítima, preestructurada y de carácter no permanente que sólo se activa cuando las circunstancias lo requieren, previo acuerdo de sus países miembros. El mando es rotatorio y de carácter bianual y se constituyó en agosto de 2006 y fue mandada inicialmente por Italia y, posteriormente, por Alemania. Ante la necesidad de relevar a Alemania, el Secretariado de las Eurofuerzas, en nombre de las naciones que las componen (Francia, Italia, Portugal y España) comunicó en diciembre de 2007 al Secretario General Adjunto y Director del Departamento de Operaciones de Paz de la ONU que EUROMARFOR estaría en condiciones de liderar la Fuerza Marítima de UNIFIL a partir del 1 de marzo de 2008, por un período inicial de seis meses, prorrogables a otros seis (BOCG. Congreso de los Diputados Núm. D-23 de 30 de mayo de 2008, p. 19 Solicitud de la autorización. BOCG. Congreso de los Diputados Núm. D-24 de 02 de junio de 2008, p. 6, DS. Congreso de los Diputados Núm. 31 de 29 de mayo de 2008, p. 2). 


\section{LAS OPERACIONES DE PAZ Y RECONSTRUCCIÓN EN EL EXTERIOR: LA LEY ORGÁNICA 5/2005}

En el periodo 1990-2010, España ha destinado 6.970 millones de euros en misiones de paz en el exterior, y del total de recursos destinados a la participación de las Fuerzas Armadas en estas misiones dos tercios de estos recursos (4.613 millones de euros) han sido presupuestados a partir de 2000. Las operaciones internacionales que han necesitado mayor financiación han sido ISAF-Afganistán (1.659 millones), SFOR-Bosnia (1.444 millones) y KFOR-Kosovo (1.004 millones) (Correa Burrows, 2010: 1-10).

Junto a este respaldo presupuestario, la relevancia social de las operaciones de paz queda acreditada sobre todo por su respaldo sociológico y por su asunción legal y política como función del ejercicio de la soberanía del Estado. Precisamente, en materia de operaciones militares de paz en el exterior, la voluntad soberana de las Cortes Generales sólo está contemplada por la Constitución de 1978 en su artículo 63.3, según el cual al Rey corresponde, previa autorización de las Cortes Generales, declarar la guerra y hacer la paz. Por su parte, el artículo 97 establece: "El Gobierno dirige la política interior y exterior, la Administración civil y militar y la defensa del Estado", sin que el artículo 8 de la Constitución de 1978 suponga que las Fuerzas Armadas tengan reconocida autonomía para sus misiones (López Ramón, 2007: 11-18). Durante su vigencia, misiones militares tan relevantes como las ejecutadas en la primera Guerra del Golfo, las guerras en la antigua Yugoslavia, Afganistán o Irak demostraron la falta de tradición española y peso político de las comisiones parlamentarias en materia de defensa, la deficiente cultura constitucional y política en materia de seguridad y la necesidad de que regular legislativamente un sistema de control parlamentario de las operaciones de las Fuerzas Armadas en el exterior. Sin legislación sectorial durante veintisiete años, el control genérico sobre los acuerdos del Consejo de Ministros en materia de operaciones militares humanitarias en el exterior se limitaba a las comunicaciones y a las comparecencias voluntarias del Gobierno en la Comisión de Defensa o en el Pleno, y las solicitadas por los Grupos Parlamentarios: proposiciones no de ley, debates, mociones, interpelaciones, preguntas escritas y orales, comparecencias y Comisiones de investigación. Por ejemplo, la Comunicación del Gobierno en la que solicita la celebración de un debate sobre el Acuerdo del Consejo de Ministros de 2 de julio de 2004, sobre participación del contingente militar español en operaciones internacionales (BOCG. Congreso de los Diputados no 49 de 6 de julio de 2004, p. 11).

En la actualidad, bajo la inspiración del principio de control del poder legislativo sobre el poder ejecutivo propio del Estado limitado, que es también Estado social, democrático y de Derecho (art. 1 de la Constitución), la LO 5/2005 regula un régimen de consulta previa, autorización, ratificación e información que, salvadas algunas excepciones como Alemania, se practica particularmente en los sistemas constitucionales resultantes de la transición democrática y en pocos de los que alcanzan una mayor madurez política (Xuclà I Costa, Pla i Boix , 2008: 7-46). En el trámite parlamentario de esta ley, el Grupo Parlamentario Popular se refirió a la autorización parlamentaria como "un error de principio": "Sólo hay dos países en la Unión Europea, concretamente Dinamarca y Alemania, donde por razones muy peculiares -en el caso de Alemania además perfectamente comprensibles por su evolución histórica- se exige esa autorización previa e incluso en Alemania hay amplias discusiones al respecto" (Boletín Oficial de las Cortes Generales. VIII Legislatura. Serie A. Proyectos de Ley. 31 de marzo de 2005. Núm. 31.1. 131/000031). 
A tal efecto, la LO 5/2005 consagra esta regulación en sustitución de lo dispuesto en la antigua LO 6/1980, de 1 de julio, sobre Criterios Básicos de la Defensa Nacional y la Organización Militar, parcialmente modificada por la LO 1/1984, de 5 de enero, completando los tres tipos de control parlamentarios más seguidos en Derecho constitucional comparado: a) el control-responsabilidad, de manera que la consulta previa y la denegación de autorización puede considerarse una fase previa de una moción reprobatoria en política exterior e incluso de la moción de censura; b) el control-inspección, directamente a través de la consulta previa, la información y la verificación de las conductas del Gobierno y, en particular, del Ministerio de Defensa; y c) el control-autorización de las misiones militares en el exterior. En el trámite parlamentario, el artículo 16 del Proyecto de Ley, rubricado Consulta al Congreso de los Diputados disponía "1. Para ordenar operaciones en el exterior que no estén directamente relacionadas con la defensa de España, el Gobierno realizará una consulta previa para recabar el parecer del Congreso de los Diputados 2. En las misiones en el exterior que, de acuerdo con compromisos internacionales, requieran una respuesta rápida o inmediata a determinadas situaciones, los trámites de consulta previa se realizarán mediante procedimientos de urgencia que permitan cumplir con dichos compromisos 3 . En los supuestos previstos en el apartado anterior, cuando por razones de máxima urgencia no fuera posible realizar la consulta previa, el Gobierno someterá al Congreso de los Diputados lo antes posible la decisión que haya adoptado". BOCG. Congreso de los Diputados, Serie A no $31-1$ de 31 de marzo de 2005 p. 6).

Al inicio de la norma citada, el artículo 2 de la LO 5/2005, establece como objetivo de la política de defensa el de "contribuir a la preservación de la paz y seguridad internacionales, en el marco de los compromisos contraídos por el Reino de España". En virtud de su artículo 17, sobre autorización del Congreso de los Diputados, para ordenar operaciones en el exterior que no estén directamente relacionadas con la defensa de España o del interés nacional, el Gobierno realizará una consulta previa y recabará la autorización del Congreso de los Diputados (López Ramón, 2007: 15-18). Según el párrafo 2, en las misiones en el exterior que, de acuerdo con compromisos internacionales, requieran una respuesta rápida o inmediata a determinadas situaciones, los trámites de consulta previa y autorización se realizarán mediante procedimientos de urgencia que permitan cumplir con dichos compromisos. En su tramitación originaria, el artículo 17 del Proyecto, rubricado Seguimiento de las operaciones establecía: "El Gobierno informará periódicamente al Congreso de los Diputados sobre el desarrollo de las operaciones de las Fuerzas Armadas en el exterior". BOCG. Congreso, Serie A n n $^{\circ} 1-1$ de 31 de marzo de 2005 p. 6. BOCG. Congreso de los Diputados, Serie A no 31-5 de 18 de mayo de 2005, p. 17-97. BOCG. Congreso de los Diputados, Serie A n n $^{\circ}$ 31-6 de 10 de junio de 2005, p. 102. Se distingue, pues, entre las operaciones militares en el exterior que afecten directamente a la soberanía de España, que no requieren autorización del Congreso de los Diputados al ubicarse en el ámbito de la función ejecutiva del Gobierno, y las que se ejecuten en cumplimiento de obligaciones internacionales, que precisan de la autorización. En estos supuestos, cuando por razones de máxima urgencia no fuera posible realizar la consulta previa, el Gobierno someterá al Congreso de los Diputados lo antes posible la decisión que haya adoptado para la ratificación, en su caso.

Estas previsiones se encuadran en el marco superior del Título III sobre Misiones de las Fuerzas Armadas y su control parlamentario, concretamente en su Capítulo I referente a las misiones en sí. Al respecto, el proyecto de Ley Orgánica de la Defensa Nacional solamente recogía en su artículo 16 (actual 17) una muy somera y abstracta referencia a "realizar una consulta previa para recabar el parecer del Congreso de los Diputados". Asimismo, en su 
artículo 17 (actual 18) se limitaba a señalar que el Gobierno informaría "periódicamente al Congreso de los Diputados" sin mayor abundamiento en ningún plazo ni capacidad real de intervención política en la política militar exterior.

Conforme al artículo 18, sobre el seguimiento de las operaciones, el Gobierno informará periódicamente, en un plazo en ningún caso superior a un año, al Congreso de los Diputados sobre el desarrollo de las operaciones de las Fuerzas Armadas en el exterior (BOCG, Senado, Serie II, de 27 de octubre de 2005 Núm. 31. Congreso 31 de marzo de 2005. Serie A. Núm. 31-1).

Pues bien, como procedimiento que refuerza el principio de equilibrio de poderes y, al mismo tiempo, refuerza el carácter asimétrico y desigual de nuestro parlamentarismo bicameral al atribuir al Congreso de los Diputados las principales funciones de las Cortes Generales, cuatro reflexiones preliminares merece el régimen español de autorización, ratificación e información parlamentarias de las operaciones de paz y reconstrucción de las Fuerzas Armadas en el exterior (Gómez-Robledo Verduzco, 2002: 99-114). En primer lugar, se trata de un ámbito delimitado materialmente de una forma ciertamente amplia, del que se excluye, conforme a dos criterios sujetos a discrecionalidad política que calificará el propio Gobierno en primera instancia, aquellas operaciones que no estén directamente relacionadas con la defensa de España o del interés nacional. En segundo lugar, y con independencia de lo que se debatió con otro tenor durante la tramitación de la LO 5/2005 en sede parlamentaria (Aranda Álvarez, 2007: 23-48), resulta dudoso que existan operaciones de paz y reconstrucción que no estén relacionadas directa o indirectamente con el interés nacional. En tercer lugar, esa delimitación material no implica que las operaciones excluidas queden fuera del régimen de control parlamentario, que siempre debe cumplimentarse al ser una función general de las Cortes Generales, ya sea a través de las técnicas generales (preguntas, interpelaciones, mociones, autorizaciones de tratados...), ya sea en el marco del artículo 17, cuyo contenido ha previsto estrictamente un procedimiento de autorización, ratificación e información en los casos de las operaciones de paz y reconstrucción. Y, en cuarto lugar, en la práctica, toda vez que desde la entrada en vigor de la Ley han sido ocho las operaciones de paz y reconstrucción que han debido ser autorizadas conforme a este procedimiento, podemos afirmar que el trámite del artículo 17 se ha convertido, por su utilización reiterada, en el régimen común o general de control de las operaciones de las Fuerzas Armadas en el exterior.

En cuanto a la competencia orgánica del procedimiento de autorización y ratificación, la solicitud se atribuye al Consejo de Ministros, si bien se contempla una delegación de funciones en la Ministra de Defensa o, en un caso, en el Ministro de Asuntos Exteriores y de Cooperación, para la realización de los trámites de consulta previa y de solicitud de autorización necesarios. Por su parte, respecto al procedimiento sobre la consulta previa, autorización o ratificación, corresponde a la Mesa de la Cámara del Congreso la tramitación de la solicitud de autorización para las Operaciones de las Fuerzas Armadas en el exterior, que a su vez compete al Gobierno de la Nación, a diferencia de otros referentes comparados en los que la aprobación parlamentaria previa se delega a una Comisión parlamentaria especial, con posible merma del grado de publicidad de los debates, trámites y acuerdos.

En relación con la competencia decisoria, al no existir completa previsión reglamentaria sobre la deliberación del asunto ni articulación procesal, su competencia decisoria se ha atribuido casuísticamente bien a la Comisión de Defensa, bien a la Mesa en virtud del artículo $31.1 .4^{\circ}$ y $5^{\circ}$ del Reglamento del Congreso. Ante esta ausencia de previsión reglamentaria, la deliberación se atribuye al Pleno del Congreso y la decisión se 
aprueba por mayoría simple, si bien en el trámite parlamentario de la LO 5/2005 se previeron mayorías cualificadas siguiendo precedentes comparados (La enmienda núm. 85, de modificación del artículo 16.1, frente al siguiente tenor "El Gobierno realizará una consulta previa para recabar el parecer del Congreso de los Diputados", defendió el siguiente texto: "El Gobierno requerirá la aprobación por mayoría absoluta del Congreso de los Diputados. Este quórum será de $2 / 3$ partes siempre que implique la participación en una acción militar ofensiva“. BOCG. Congreso de los Diputados n 31,5 de 18 de mayo de 2005 , pp. 39 y 40). Todo lo cual permanece a la espera de la necesaria reforma del Reglamento o de las pertinentes resoluciones interpretativas en esta materia que regulen una tipificación competencial de la Comisión competente para ejercer los instrumentos de información, consulta previa, autorización y ratificación: el Pleno, la Comisión de Defensa, la Comisión de Asuntos Exteriores o una Comisión Mixta.

El objeto del acuerdo del Consejo de Ministros se refiere a la solicitud de información, consulta previa, autorización o ratificación del Congreso de los Diputados para participar en una Misión internacional o de la Unión Europea, lo que en el caso del contenido de la información debería regularse con carácter reglado (El contingente español se compone de un total de 38 efectivos, incluyendo el personal desplegado en los siguientes elementos: Jefatura de la Misión; Célula de apoyo en Bruselas; Cuartel General de la Misión en Kampala (Uganda); Base de adiestramiento en Bihanga (Uganda) y otros lugares cercanos que se pudieran necesitar. A este personal se podrá añadir con carácter restrictivo y temporal aquel que en función del desarrollo de la misión se precise). Por lo general, la solicitud incluye el acuerdo de delegación del Consejo de Ministros en la Ministra de Defensa para la realización de los trámites de consulta previa y de solicitud de autorización necesarios(http://www.congreso.es/public_oficiales/L9/CONG/BOCG/D/D_375.PDF\#pag e=23, PP. 23 Y 24. Congreso 16 de abril de 2010. Serie D. Núm. 375. BOCG). Además, existe una partida presupuestaria propia para los gastos derivados de la participación española en estas misiones con cargo a la rúbrica presupuestaria "Participación de las FAS en Operaciones de Mantenimiento de la Paz" (Participación de las FAS en Operaciones de Mantenimiento de la Paz", aplicación 14.03.122M.228 del Ministerio de Defensa. Madrid, 9 de abril de 2010). Por último, en cuanto a las garantías y los principios de eficacia jurídica, se prevé la publicidad que de estas autorizaciones, que se realiza en el Boletín Oficial de las Cortes Generales.

\section{REFLEXIONES CONCLUSIVAS}

Debemos finalizar realizando cinco breves reflexiones acerca de la participación española en la aplicación de los acuerdos de paz, en la gestión de las tareas de reconstrucción postconflicto, en las operaciones de ayuda humanitaria y en la lucha contra la piratería en el marco de la denominada Estrategia de la Cooperación para la Construcción de la Paz, como contenidos del Estado social de Derecho en su dimensión internacional.

En primer lugar, se trata de una actividad estatal que ha logrado y mantenido un gran respaldo sociológico y político, como demuestran los mencionados estudios del Centro de Investigaciones Sociológicas y del Real Instituto Elcano. Esta aceptación social de las operaciones de paz, que es compatible con la percepción del peligro que suponen, ha sido facilitada por el régimen de parlamentarización (control, información) de las operaciones en el exterior emprendido durante la IX Legislatura. 
En segundo lugar, se trata de una competencia del Estado que el Gobierno dirige y organiza a través de las Fuerzas Armadas bajo el control parlamentario residenciado en el Congreso de los Diputados, sede del ejercicio de la soberanía del pueblo, lo cual ha dotado de legitimidad política originaria a esta acción exterior.

En tercer lugar, la fundamentación jurídica de las solicitudes de autorización y ratificación ha sido adoptada, en ocho ocasiones, por el Congreso de los Diputados, quienes gestionan esta función, bien a priori (autorización), bien a posteriori (ratificación), comprobando las justificaciones que ofrecen las normas jurídico-internacionales y el Derecho de la Unión Europea, en cumplimiento de los principios de motivación, transparencia y publicidad.

En cuarto lugar, esta publicidad parlamentaria de la tramitación de las operaciones, como principio exigido por la LO 5/2005, que es muy relevante en la reconstrucción postconflicto, resulta fundamental para el cumplimiento de fines tan vinculados al Estado Constitucional como la consolidación institucional fundada en principios democráticos, la participación política o la reforma de la Administración de justicia.

$\mathrm{Y}$, en quinto lugar, debe advertirse la necesidad de una reforma legislativa que, a partir del acervo de definiciones ya consolidadas en el Derecho de Naciones Unidas y del ordenamiento de la Unión Europea, actualice los conceptos y clasificaciones sobre las operaciones de paz que actualmente se regulan de forma fragmentaria y obsoleta por la legislación y las normas reglamentarias españolas (construcción de la paz, operación de paz, acción humanitaria).

En síntesis, el cumplimiento de las funciones actuales del Estado en su dimensión internacional a través de las operaciones de paz y reconstrucción, y la fundamentación derivada de las resoluciones de Naciones Unidas y de la Unión Europea, permiten constatar el avance de nuestro sistema constitucional hacia la consolidación de un Estado social comprometido con la acción humanitaria en el exterior, respaldado sociológicamente por la ciudadanía, legitimado por las leyes y controlado por las Cortes Generales.

\section{BIBLIOGRAFÍA}

ARANDA ÁLVAREZ, E. (2007): "La ley de defensa nacional y la participación de España en operaciones de mantenimiento de la paz", Administración \& Ciudadanía: Revista da Escola Galega de Administración Pública. Vol. 2, nº 1, pp. 23-48.

BOUTROS-GHALI, B. (1992): Un programa de paz. Diplomacia preventiva, establecimiento de la paz y mantenimiento de la paz, Nueva York, Naciones Unidas.

CORREA BURROWS, P. (2010): ¿Cómo se financian y cuánto le cuestan a España las misiones internacionales de paz? Observatorio de Política Exterior de la Fundación Alternativas. №: 143/2010, pp. 1-10.

GÓMEZ-ROBLEDO VERDUZCO, A. (2002): “Consideraciones en torno a las operaciones para el mantenimiento de la paz", Boletín Mexicano de Derecho Comparado. 103, pp. 99-114.

LÓPEZ RAMÓN, F. (2007): "La evolución democrática de la defensa nacional”, Revista Española de Derecho Constitucional, 80, pp. 11-48.

MARTÍNEZ ISIDORO, R. (2009): “Las Operaciones de Apoyo a la Paz”. Documentos de Trabajo. Real Instituto Elcano de Estudios Internacionales y Estratégicos, núm. 25.

NACIONES UNIDAS. Declaración del Milenio. A/RES/55/2. Asamblea General Distr. General 13 de septiembre de 2000. Quincuagésimo quinto período de sesiones. Resolución aprobada por la Asamblea General. Declaración del Milenio. Apart. 6. 
PÉREZ DE ARMIÑO, K. y AREIZAGA, M. (coords.) (2002): Diccionario de Acción Humanitaria y Cooperación al Desarrollo. Hegoa, Universidad del País Vasco - Barcelona: Icaria.

PUERTAS CRISTÓBAL, E y ASTORGA, G. (2010): La Universidad ante los desastres naturales: Acción Humanitaria y Desarrollo. Cádiz. Servicio de Publicaciones de la Universidad de Cádiz

REY MARCOS, F.; THIEUX, L. y NÚÑEZ, J. A. (2007): Fuerzas Armadas y Acción Humanitaria: Debates y propuestas. IECAH, Documento de trabajo $\mathrm{n}^{\circ} 13$. Madrid: Fundación Carolina.

XUCLÀ I COSTA, J. y PLA I BOIX, A. M. (2008): "La autorización y control parlamentario de las misiones del Ejército en el exterior: la falta de un procedimiento común", Revista de las Cortes Generales, 74, pp. 7-46.

\section{Breve currículo:}

\section{Esther Puertas Cristóbal}

Profesora Asociada de la Universidad de Cádiz. Técnica en Cooperación al Desarrollo (Dirección General de Acción Social y Solidaria UCA). Profesora y coordinadora del Itinerario de Agentes de Salud en contextos en Desarrollo del Máster oficial en Investigación e Innovación en Cuidados de Salud de la Universidad de Cádiz y del Curso de Cooperación al Desarrollo y Gestión de Postconflictos. Situaciones de Emergencias y Ayuda Humanitaria del Máster Oficial en Cultura de Paz, Educación y Derechos Humanos de la Universidad de Cádiz. Miembro del Grupo de Investigación HUM 055 del PAIDI de Investigación Salud, Género y Desarrollo. Estancias investigadoras y docentes en Nicaragua (participación en la Maestría en Salud Sexual y Reproductiva de la UNAN-Managua). Autora de varias publicaciones en materia de cooperación al desarrollo y acción humanitaria.

\section{José Joaquín Fernández Alles}

Profesor Titular de Universidad de Derecho Constitucional. Universidad de Cádiz. Doctor en Derecho. Premio de Estudios Constitucionales 1812, del Centro de Estudio Constitucionales 1812 (Jurado: Clavero Arévalo, Pérez-Llorca, Jiménez Sánchez). Autor de sesenta y dos publicaciones (Revista Española de Derecho Constitucional, Teoría y Realidad Constitucional, Revista de las Cortes Generales, Boletín Mexicano de Derecho Comparado...). Miembro del Proyecto I+D Consolider Ingenio Tiempo de los Derechos (Dir. G. Peces Barba). Responsable de seis Proyectos de Cooperación Interuniversitaria y de varios proyectos de investigación. Profesor del Máster Interuniversitario de Cultura de la Paz de la Universidad de Cádiz. Miembro del Instituto de Investigación de Europa Atlántico Mediterráneo de la Universidad de Cádiz. Responsable del Grupo SEJ-352 del Plan Andaluz de Investigación. Varias estancias en el extranjero (Harvard, Roma, Marruecos...). 